\title{
Adolescent undernutrition and early adulthood bone mass in an urbanizing rural community in India
}

\author{
Mika Matsuzaki ${ }^{1} \cdot$ Hannah Kuper $^{2}$ - Bharati Kulkarni ${ }^{3}$ George B. Ploubidis ${ }^{4}$. \\ Jonathan C. Wells ${ }^{5}$ Kankipati Vijaya Radhakrishna ${ }^{3}$ - Poornima Prabhakaran ${ }^{6}$. \\ Vipin Gupta $^{7}$ - Gagandeep Kaur Walia $^{6}$ - Aastha Aggarwal ${ }^{6}$ • Dorairaj Prabhakaran ${ }^{8}$. \\ K. V. Rameshwar Sarma ${ }^{3}$. George Davey Smith ${ }^{9}$ - Yoav Ben-Shlomo ${ }^{10}$ - Sanjay Kinra ${ }^{1}$
}

Received: 20 February 2015 / Accepted: 14 August 2015 / Published online: 1 September 2015

(C) The Author(s) 2015. This article is published with open access at Springerlink.com

\begin{abstract}
Summary The long-term effects on bone health of nutritional status in adolescence are unclear. The impact of adolescent and current body mass on bone mass in young adulthood in rural India was assessed. Current lean mass was a more important determinant of bone mass than thinness during adolescence in this population.

Purpose/introduction Adolescence is a crucial period for skeletal growth. However, the long-term effects on bone health of nutritional status in adolescence, particularly in the context of nutritional transition, are unclear. The current manuscript assessed the impact of adolescent and current body size on bone mass in young adulthood in an Indian rural community that is undergoing rapid socioeconomic changes.

Methods The Andhra Pradesh Children and Parents Study is a prospective cohort study in Hyderabad, India. In 2003-2005, the study collected anthropometric and cardiovascular data on adolescents (mean age $=16$ years old). The second and third waves of the study in 2009-2012 collected data on current anthropometric measures, areal bone mineral density (aBMD) in hip and
\end{abstract}

Mika Matsuzaki

mika.matsuzaki@lshtm.ac.uk

1 Department of Non-communicable Disease Epidemiology, London School of Hygiene and Tropical Medicine, Keppel Street, London WC1E 7HT, UK

2 Department of Clinical Research, London School of Hygiene and Tropical Medicine, Keppel Street, London WC1E 7HT, UK

3 National Institute of Nutrition, Indian Council of Medical Research Tarnaka, Jamai-Osmania, Hyderabad 500 007, India

4 Department of Population Health and Statistics Centre for Longitudinal Studies, Institute of Education, University of London, 20 Bedford Way, WC1H 0AL London, UK lumbar spine (L1-L4) measured by dual-energy X-ray absorptiometry, and living standards of the trial participants who were now young adults (mean age $=22$ years old).

Results The median body mass index (BMI) of the 722 participants included in this analysis was $16.8 \mathrm{~kg} / \mathrm{m}^{2}$ during adolescence, while the median BMI as young adults was $19.3 \mathrm{~kg} / \mathrm{m}^{2}$. Lower aBMD during adulthood was associated with lower adolescent BMI ( $\beta$ (95\% confidence interval) for hip aBMD 0.017 (0.013 to 0.022) and LS aBMD 0.012 (0.008 to 0.016$)$ ). This association was attenuated upon adjustment for current fat and lean mass ( $\beta(95 \% \mathrm{CI})$ for hip aBMD 0.00 $(-0.005$ to 0.005$)$ and LS aBMD 0.005 (0.000 to 0.01$)$ ). There was clear evidence for positive associations between aBMDs and current lean mass.

Conclusions Current lean mass was a more important determinant of bone mass than thinness during adolescence in this population. Weight gain during late adolescence and young adulthood coupled with improvement in lean mass may help to mitigate any adverse effects that pre-adulthood undernutrition may have on bone mass accrual.

5 Childhood Nutrition Research Centre, UCL Institute of Child Health, 30 Guilford St, WC1N 1EH London, UK

6 Public Health Foundation of India, ISID Complex, 4 Institutional Area, Vasant Kunj, 110070 New Delhi, India

7 Department of Anthropology, University of Delhi, New Delhi, India

8 Centre for Chronic Disease Control, 4th Floor, Plot no. 47, Sector 44, Near Metro Huda Center, Gurgaon, Haryana 122002, India

9 MRC Integrative Epidemiology Unit, School of Social and Community Medicine, University of Bristol, BS8 2BN Bristol, UK

10 School of Social and Community Medicine, Canynge Hall, 39 Whatley Road, BS8 2PS Bristol, UK 
Keywords Undernutrition · Adolescence · Bone mineral density $\cdot$ Longitudinal

\section{Introduction}

Suboptimal peak bone mass is associated with higher risk of osteoporotic fractures in later life $[1,2]$. Studies from high income countries have shown that $90 \%$ of peak bone mass is accrued before age 18 in healthy individuals $[1,3,4]$. Skeletal growth during adolescence is therefore an important determinant of peak bone mass. Large body size, high level of weight-bearing physical activity, and adequate micronutrient intake are some of the key determinants of bone mass accrual [1].

Undernutrition is commonly observed in low and middle income countries (LMICs). In India, the prevalence of undernutrition remains high although it has been slowly declining over the last 2 decades [5, 6]. As a result, some young adults who experienced undernutrition during childhood and adolescence have attained at least normal body mass index as adults [7].

A number of studies have suggested positive associations between adult bone mass and birthweight as well as weight during infancy [8-10]. On the other hand, association between peak bone mass and thinness during adolescence has not been adequately studied in lean populations from LMICs. Some studies from high income countries examined longitudinal effects of anorexia nervosa during adolescence and showed that successful recovery from anorexia nervosa may mitigate some of the negative effects of low body weight during adolescence $[11,12]$. Since adolescence is a crucial period for skeletal growth, it is important to understand whether undernutrition during adolescence has any long-term effects on bone mass.

While studies have generally found a positive association between body mass and bone mass, fat and lean mass may be differently associated with bone mass [13-15]. Lean mass is influenced by both diet and physical activity level. Weightbearing physical activity during adolescence is associated with higher bone mass $[4,16]$. It is therefore important to understand how gains in overall weight, fat mass, and lean mass may contribute to skeletal development in young adults who experienced nutritional transition during adolescence.

The Andhra Pradesh Children and Parents Study (APCAPS) is a prospective cohort study from southern India. The study community has been experiencing nutritional transition due to urbanization over the past decade. The current manuscript assessed whether being underweight during adolescence is associated with lower peak bone mass in young adults, some of whom have experienced improvements in nutritional status since adolescence.

\section{Methods}

\section{Study design}

The analyses in this study used data from three waves of data collection (2003-2005, 2009-2010, and 2010-2012) of the APCAPS study, established through long-term follow up of the Hyderabad Nutrition Trial (HNT). The HNT studied impact of the Integrated Child Development Services (ICDS) scheme, a national community outreach program providing food supplementation along with health, hygiene, and nutrition education, immunization, anemia control, and basic health care to pregnant and lactating women and children under the age of 6 years [17].

\section{Initial trial (1987-90) and the first wave of data collection (W1: 2003-5)}

A detailed description of the initial trial (HNT) and the first wave of data collection (the first follow-up of the HNT) have previously been published [18]. Briefly, a controlled "stepped wedge design" study was conducted in 1987-1990, using the opportunity afforded by the incremental expansion of ICDS program. A total of 29 villages in two adjacent administrative areas near Hyderabad city in India were selected, one with ICDS program already in place (15 intervention villages) and the other awaiting implementation (14 control villages). In the intervention villages, a nutritional supplement made of corn-soya blend and soybean oil was available daily to all pregnant and lactating women and children under 6 years. The meal (upma) contained, on average, 2.09 MJ and 20$25 \mathrm{~g}$ protein for pregnant and lactating women and about $1.25 \mathrm{MJ}$ and $8-10 \mathrm{~g}$ protein for children under 6 years old. The supplementation was associated with a small but statistically robust ( $61 \mathrm{~g} ; 95 \%$ CI 18 to $104 \mathrm{~g}$; $p=0.007$ ) increase in the birth weight of the offspring [18]. During the first wave of data collection in 2003-2005, 1165 adolescents aged 1318 years who were still resident in these villages were reexamined [18]. The adolescents in the intervention villages were $14 \mathrm{~mm}(95 \%$ CI 4 to $23 \mathrm{~mm} ; p=0.007)$ taller and had more favorable measures of insulin resistance and arterial stiffness as shown by a $20 \%(95 \%$ CI 3 to $39 \% ; p=0.02)$ lower homoeostasis model assessment score, which describes levels of insulin resistance, and $3.3 \%(95 \%$ CI 1 to $5.7 \%$; $p=$ 0.008 ) lower augmentation index.

\section{The second and third waves of data collection (W2/3: 2009-2012)}

Since the second and third waves of data collection were conducted within a relatively short period of time (2009-2012), the analyses in this manuscript combined data from these two waves of data collection (W2/3). W2/3 examined markers for 
chronic diseases affecting cardiovascular, musculoskeletal, and mental health. All consenting participants underwent DXA measurements at the National Institute of Nutrition (NIN), Hyderabad, and physical measurements at NIN (W2) or the village clinics (W3). In cases where participants attended both waves of data collection, the data from the third wave were used, unless there were artifacts in DXA scans from the W3, which prompted the use of data from W2.

The present analyses were restricted to participants from the first wave of data collection who also underwent DXA scans during $\mathrm{W} 2 / 3$.

\section{Measurements}

\section{Questionnaire data (W1/2/3)}

A semi-structured questionnaire was administered to all participants by a trained interviewer. A subset of questions (14/ 29) from the Standard of Living Index (SLI) in the National Health Family Survey-2, a summary measure of household level asset-based scale devised for Indian surveys, was used to estimate socioeconomic position, as joint family structures are common in rural India [19]. We collected information on the quality of house, toilet facilities, source of lighting and drinking water, ownership of clock, radio, television, bicycle, motorcycle, car, refrigerator, telephone, and agricultural land. These items were weighted to give a maximum score of 34 , using weights developed by the International Institute of Population Science in India [19]. Education was classified in four levels: no formal education, primary (1 to 4 standard), secondary (5 to 12 standard), and beyond secondary level education. Current tobacco use was defined as smoking, chewing, or snuffing tobacco in the last 6 months.

\section{Puberty (W1)}

Four puberty stages were set based on sexual maturation on the basis of time since the onset of menstruation (girls) and testicular volume (boys) [20]. The boys assessed testicular volume in private, using Prader's orchidometer with volumes ranging from 1 to $25 \mathrm{ml}$. This self-assessment was validated against measurements by clinicians in an external sub-study [20].

\section{Anthropometric data (W1/2/3)}

Weight was measured to the nearest $0.1 \mathrm{~kg}$ with a digital SECA balance, and standing height was measured to the nearest $1 \mathrm{~mm}$ with a plastic stadiometer (Leicester height measure). Measurements were taken twice, and the average of two values was used in the analysis (coefficients of variation for height $0.67 \%$; weight $0.09 \%$ ). Body mass index (BMI) was calculated as weight $(\mathrm{kg}) /$ height $\left(\mathrm{m}^{2}\right)$. Cutoff points of BMI $\leq 17.0$ and $\leq 18.5$ were used for underweight in adolescence and adulthood respectively [21, 22].

\section{DXA scanning (W2/3)}

Bone mass measurements were assessed with DXA on a Hologic Discovery A model. The whole body scan was performed with the participant supine on the scanning bed with their arms resting by their sides. On the basis of repeated measurements for 30 participants with Hologic Discovery A, the coefficients of variation were determined to be $0.7 \%$ for hip bone mineral density (BMD), $1.3 \%$ for LS aBMD, and $0.9 \%$ for whole-body aBMD. Women suspected of pregnancy were excluded from DXA scanning, and the scans were taken only after confirming the negative pregnancy by conducting urine pregnancy test. Standard Hologic software options were used to define regions of the body (head, arms, trunk, and legs). Scans were coded for artifacts by a visual inspection, and those with major movement as well as incomplete scans were excluded from the present analyses. For lumbar spine (LS) scans, pathological changes such as osteoarthritis affecting two or more vertebrae were excluded; if only one vertebra was affected, the scan was reanalyzed after the affected part was excluded [23]. Areal bone mineral density (aBMD in $\mathrm{g} / \mathrm{cm}^{2}$ ) was calculated from bone mineral content (BMC in $\mathrm{g}$ ) and bone area (BA in $\mathrm{cm}^{2}$ ) for total hip and lumbar spine (L1-L4). Fat and lean mass indexes (FMI and LMI) were based on fat and lean mass $(\mathrm{kg})$ from whole-body scans/height $\left(\mathrm{m}^{2}\right)$. Major movements were counted as artifacts and removed from analysis with fat and lean mass.

\section{Statistical analysis}

Descriptive statistics were calculated for each sex. The associations of hip and lumbar spine BA, BMC, and aBMD with adolescent body size were modeled in multilevel regression models that accounted for village clusters (29 villages). FMI was log-transformed because it had a positively skewed distribution. Complete-case analysis was used.

Four models were fitted for each of the two outcome variables (hip and LS aBMD): Model 1 assessed each of the explanatory variables (adolescent BMI, current (young adulthood) BMI, current FMI, current LMI), adjusting for sex, age at $\mathrm{W} 1$, age at $\mathrm{W} 2 / 3$, height at $\mathrm{W} 1(\mathrm{~cm})$, and height at $\mathrm{W} 2 / 3$ $(\mathrm{cm})$. Model 2 examined the association between aBMD and adolescent BMI, adjusting for current BMI, age at $\mathrm{W} 1$, age at $\mathrm{W} 2 / 3$, sex, height at $\mathrm{W} 1$, and height at $\mathrm{W} 2 / 3$. In model 3, current BMI in model 2 was replaced with current FMI and LMI. Model 4 replaced current BMI in model 2 with conditional BMI to examine the effect of change in BMI, by using residuals from a regression model in which current BMI was regressed on adolescent BMI. We also adjusted model 3 for other potential confounders such as puberty stages at W1, 
adolescent height, current height, adolescent SLI, current SLI, and current tobacco use. Interaction terms between sex and adolescent BMI, current FMI, current LMI, and change in BMI were examined in models 3 and 4. There was weak evidence for an interaction with current FMI for LS aBMD, where the effect of FMI was slightly higher in female (the interaction term $\beta$ : $0.08 ; p=0.04$ ). Residuals from the multilevel models were checked for normality (Shapiro-Wilk test) and heteroscedasticity and found reasonably normally distributed and homoscedastic at each level.

All analyses were conducted using $R$, version 3.0.0, and multilevel modeling was done with nlme version 3.1-109.

\section{Quality control}

We produced detailed protocols and regularly checked compliance to standardize the work of the fieldwork team. The anthropometric equipment was calibrated at the start of every clinic. The aBMD estimation process was automated in software, which reduces the potential for bias arising from the DXA technician. Hip and LS DXA scans were analyzed by a single trained technician. For quality assurance of DXA scans, a spine phantom was scanned every day to check for acceptable ranges.

\section{Ethics statement}

The study received approvals from the ethics committees of the NIN (Hyderabad, India), the Indian Council of Medical Research (ICMR), Centre for Chronic Disease Control, and London School of Hygiene and Tropical Medicine (London, UK). Approval was also sought from the village heads and their panchayats in each of the 29 villages. Written informed consent or witnessed thumbprint if illiterate was obtained from the participants prior to their inclusion in the study.

\section{Result}

Of the 1165 participants of the first wave of data collection (W1), 722 participants (62\%) had their height and weight measured both as adolescents and as young adults and also underwent DXA scans during the second and third waves of data collection (W2/3). Of those, scans without major artifacts were available in 710 (98\%) participants for hip aBMD and 715 (99\%) for lumbar spine aBMD. Eighty-seven percent of the participants also had scans without major artifacts for whole-body estimation of fat and lean mass. Information on
Table 1 Characteristics of the subjects who participated in the Andhra Pradesh Parents and Children Study both in 20032005 (W1) and in 2009-2012 (W2/3)

\begin{tabular}{|c|c|c|c|c|c|c|}
\hline & \multicolumn{3}{|c|}{ Women } & \multicolumn{3}{|l|}{ Men } \\
\hline & $n^{\mathrm{c}}$ & W1 & $\mathrm{W} 2 / 3$ & $n^{\mathrm{c}}$ & W1 & $\mathrm{W} 2 / 3$ \\
\hline Age (year) & 220 & $15.8(1)$ & $22(1.3)$ & 502 & $15.9(0.9)$ & $21.8(1.3)$ \\
\hline Height (cm) & 220 & $151.2(5.9)$ & $153.1(5.6)$ & 502 & $158.5(8.7)$ & $167(6.2)$ \\
\hline Weight (kg) & 220 & $40.6(6)$ & $45.9(8.2)$ & 502 & $41.9(7.5)$ & $56.0(9.4)$ \\
\hline Body mass index $\left(\mathrm{kg} / \mathrm{m}^{2}\right)$ & 220 & $17.7(2.2)$ & $19.6(3.2)$ & 502 & $16.6(1.9)$ & $20.1(3)$ \\
\hline Fat mass index $\left(\mathrm{kg} / \mathrm{m}^{2}\right)$ & 216 & $n / a$ & $5.8(2)$ & 499 & $n / a$ & $3.4(1.6)$ \\
\hline Lean mass index $\left(\mathrm{kg} / \mathrm{m}^{2}\right)$ & 216 & $n / a$ & $13.1(1.5)$ & 499 & $n / a$ & $15.9(1.8)$ \\
\hline SLI & 217 & $12.9(5)$ & $18.1(4.7)$ & 499 & $10.6(4.3)$ & $18.7(4.3)$ \\
\hline Occupation (\%) & 220 & & & 502 & & \\
\hline Student $^{\mathrm{b}}$ & & 84.2 & 27.3 & & 85.5 & 34.3 \\
\hline Employed & & 15.8 & 32.3 & & 12 & 61.2 \\
\hline Neither & & 11.7 & 40.5 & & 2.6 & 4.6 \\
\hline Tobacco use $(n)^{\mathrm{a}}$ & 215 & & & 500 & & \\
\hline Current & & 0 & 2 & & 1 & 85 \\
\hline Former & & 0 & 0 & & 0 & 3 \\
\hline Never & & 215 & 220 & & 499 & 415 \\
\hline
\end{tabular}

All values are mean (sd) unless otherwise noted

W1 the first wave of data collection (2003-2005), W2/3 the second and third waves of data collection (20092012), SLI standard of living index, $n / a$ not available

${ }^{a}$ Current tobacco use included smoking, chewing, or snuffing tobacco in the last 6 months; former users stopped using tobacco products 6 months ago or more

${ }^{\mathrm{b}}$ Student for W1 included one man who worked and studied at the same

${ }^{\mathrm{c}}$ All $n$ were same for $\mathrm{W} 1$ and W2/3 except that SLI was available for 219 women in W2/3. Tobacco use information was available for 222 women in W2/3 
Table 2 Mean hip and lumbar spine bone mass of participants of the Andhra Pradesh parents and children study in 2009-2012 (W2/3)

\begin{tabular}{llllll}
\hline \multirow{2}{*}{ Total hip } & \multicolumn{2}{l}{ Women } & & Men \\
\cline { 2 - 3 } \cline { 5 - 6 } & $n$ & Mean $(\mathrm{sd})$ & & $n$ & Mean $(\mathrm{sd})$ \\
\hline BA $\left(\mathrm{cm}^{2}\right)$ & 217 & $28.43(2.59)$ & & 493 & $35.83(3.44)$ \\
BMC $(\mathrm{g})$ & 217 & $23.92(3.98)$ & & 493 & $34.25(5.36)$ \\
BMD $\left(\mathrm{g} / \mathrm{cm}^{2}\right)$ & 217 & $0.837(0.096)$ & 493 & $0.952(0.115)$ \\
Lumbar spine & & & & \\
BA $\left(\mathrm{cm}^{2}\right)$ & 216 & $48.81(4.89)$ & & 499 & $57.56(5.63)$ \\
BMC $(\mathrm{g})$ & 216 & $42.76(8.02)$ & 499 & $54.68(8.99)$ \\
BMD $\left(\mathrm{g} / \mathrm{cm}^{2}\right)$ & 216 & $0.869(0.104)$ & 499 & $0.945(0.105)$ \\
\hline
\end{tabular}

$B A$ bone area, $B M C$ bone mineral content, $B M D$ bone mineral density

the other variables including SLI and occupation was available for $\geq 99 \%$ of the participants.

Table 1 summarizes the key characteristics of the participants. Fifty-six percent of the participants were underweight $(\mathrm{BMI}<17)$ during adolescence. The participants were still lean as young adults although the percentage of underweight individuals $(\mathrm{BMI} \leq 18.5)$ decreased to $38 \%$. A majority of the participants were students during W1, but only a third of the participants were students during $\mathrm{W} 2 / 3$. Women were more likely to be unemployed and engaged in household work as young adults. Both hip and lumbar spine aBMD values were generally lower than the reference values for the Indian population (Table 2) [24]. Underweight adults $(\mathrm{BMI} \leq 18.5)$ showed lower aBMD than others with normal BMI (data not shown).

Positive association between current aBMD and adolescent BMI was attenuated upon adjustment for current BMI in hip, but the association remained for lumbar spine (Tables 3 and 4). There was no strong evidence of interactions between the change in BMI between $\mathrm{W} 1$ and $\mathrm{W} 2 / \mathrm{W} 3$ and adolescent BMI (data not shown). In model 3, current lean mass index was strongly associated with current aBMD, whereas there was no strong evidence for association between current aBMD and adolescent BMI or current fat mass index. Model 4 showed positive associations between current aBMDs and conditional BMI. Adjustment for other potential confounders (puberty stages at W1, adolescent height, current height, adolescent SLI, current SLI, and current tobacco use) did not materially change the results.

Table 3 Multivariable models examining associations between body mass index during adolescence (2003-2005) and current bone mineral density (2009-2012) in hip in young adults of the Andhra Pradesh children and parents study (2003-2012)

\begin{tabular}{|c|c|c|c|c|c|c|c|c|}
\hline & \multicolumn{8}{|l|}{ Hip BMD } \\
\hline & \multicolumn{2}{|l|}{ Model 1} & \multicolumn{2}{|l|}{ Model 2} & \multicolumn{2}{|l|}{ Model 3} & \multicolumn{2}{|l|}{ Model 4} \\
\hline & \multicolumn{2}{|l|}{$\beta$} & \multicolumn{2}{|l|}{$\beta$} & \multicolumn{2}{|l|}{$\beta$} & \multicolumn{2}{|l|}{$\beta$} \\
\hline & $(95 \% \mathrm{CI})$ & $p$ & $(95 \% \mathrm{CI})$ & $p$ & $(95 \% \mathrm{CI})$ & $p$ & $(95 \% \mathrm{CI})$ & $p$ \\
\hline Adolescent BMI & $\begin{array}{l}0.017 \\
(0.013 \text { to } 0.022)\end{array}$ & $<0.001$ & $\begin{array}{l}0.003 \\
(-0.003 \text { to } 0.008)\end{array}$ & 0.32 & $\begin{array}{l}0.00 \\
(-0.005 \text { to } 0.005)\end{array}$ & 0.97 & $\begin{array}{l}0.015 \\
(0.011 \text { to } 0.019)\end{array}$ & $<0.001$ \\
\hline Current BMI & $\begin{array}{l}0.015 \\
(0.012 \text { to } 0.017)\end{array}$ & $<0.001$ & $\begin{array}{l}0.014 \\
(0.01 \text { to } 0.017)\end{array}$ & $<0.001$ & & & & \\
\hline Current FMI & $\begin{array}{l}0.087 \\
(0.062 \text { to } 0.113)\end{array}$ & $<0.001$ & & & $\begin{array}{l}-0.018 \\
(-0.047 \text { to } 0.011)\end{array}$ & 0.23 & & \\
\hline Current LMI & $\begin{array}{l}0.03 \\
(0.026 \text { to } 0.034)\end{array}$ & $<0.001$ & & & $\begin{array}{l}0.032 \\
(0.026 \text { to } 0.038)\end{array}$ & $<0.001$ & & \\
\hline Conditional $\mathrm{BMI}^{\mathrm{a}}$ & $\begin{array}{l}0.015 \\
(0.012 \text { to } 0.019)\end{array}$ & $<0.001$ & & & & & $\begin{array}{l}0.014 \\
(0.01 \text { to } 0.017)\end{array}$ & $<0.001$ \\
\hline
\end{tabular}

Conditional BMI was estimated from current BMI regressed on adolescent BMI

Model 1 is a base model examining association between BMD and each of four explanatory variables (adolescent BMI, adulthood BMI, adulthood fat mass, and adulthood lean mass), adjusting for sex, age at the first wave of data collection (W1) in 2003-2005 (adolescence), age at the second and third waves (W2/3) in 2009-2012 (current/adulthood), height at W1 (cm), and height at W2/3 (cm)

Model 2 examined association between adolescent BMI $\left(\mathrm{kg} / \mathrm{cm}^{2}\right)$ and adulthood BMD $\left(\mathrm{g} / \mathrm{cm}^{2}\right)$ adjusting for current BMI, sex, age at W1, age at W2/3, height at W1, and height at W2/W3

Model 3 examined association between adolescent BMI and adulthood BMD, adjusting for current FMI ( $\left.\mathrm{kg} / \mathrm{m}^{2}\right)$, current $\mathrm{LMI}\left(\mathrm{kg} / \mathrm{m}^{2}\right)$, sex, age at W1, and age at $\mathrm{W} 2 / \mathrm{W} 3$, height at $\mathrm{W} 1$, and height at W2/W3

Model 4 examined association between adolescent BMI and adulthood BMD, adjusting for conditional BMI, sex, age at W1, age at W2/3, height at W1, and height at $\mathrm{W} 2 / \mathrm{W} 3$

$B M I$ body mass index $\left(\mathrm{kg} / \mathrm{m}^{2}\right), F M I$ fat mass index $\left(\mathrm{kg} / \mathrm{m}^{2}\right.$, log-transformed), $L M I$ lean mass index $\left(\mathrm{kg} / \mathrm{m}^{2}\right)$ 
Table 4 Multivariable models examining associations between body mass index during adolescence (2003-2005) and current bone mineral density (2009-2012) in the lumbar spine in young adults of the Andhra Pradesh children and parents study (2003-2012)

\begin{tabular}{|c|c|c|c|c|c|c|c|c|}
\hline & \multicolumn{8}{|l|}{ LS BMD } \\
\hline & \multicolumn{2}{|l|}{ Model 1} & \multicolumn{2}{|l|}{ Model 2} & \multicolumn{2}{|l|}{ Model 3} & \multicolumn{2}{|l|}{ Model 4} \\
\hline & \multicolumn{2}{|l|}{$\beta$} & \multicolumn{2}{|l|}{$\beta$} & \multicolumn{2}{|l|}{$\beta$} & \multicolumn{2}{|l|}{$\beta$} \\
\hline & $(95 \% \mathrm{CI})$ & $p$ & $(95 \% \mathrm{CI})$ & $p$ & $(95 \% \mathrm{CI})$ & $p$ & $(95 \% \mathrm{CI})$ & $p$ \\
\hline Adolescent BMI & $\begin{array}{l}0.012 \\
(0.008 \text { to } 0.016)\end{array}$ & $<0.001$ & $\begin{array}{l}0.006 \\
(0.001 \text { to } 0.011)\end{array}$ & 0.03 & $\begin{array}{l}0.005 \\
(0.00 \text { to } 0.01)\end{array}$ & 0.06 & $\begin{array}{l}0.011 \\
(0.007 \text { to } 0.015)\end{array}$ & $<0.001$ \\
\hline Current BMI & $\begin{array}{l}0.008 \\
(0.006 \text { to } 0.011)\end{array}$ & $<0.001$ & $\begin{array}{l}0.006 \\
(0.003 \text { to } 0.009)\end{array}$ & $<0.001$ & & & & \\
\hline Current FMI & $\begin{array}{l}0.048 \\
(0.024 \text { to } 0.072)\end{array}$ & $<0.001$ & & & $\begin{array}{l}-0.013 \\
(-0.043 \text { to } 0.017)\end{array}$ & 0.41 & & \\
\hline Current LMI & $\begin{array}{l}0.016 \\
(0.012 \text { to } 0.02)\end{array}$ & $<0.001$ & & & $\begin{array}{l}0.014 \\
(0.008 \text { to } 0.02)\end{array}$ & $<0.001$ & & \\
\hline Conditional $\mathrm{BMI}^{\mathrm{a}}$ & $\begin{array}{l}0.007 \\
(0.004 \text { to } 0.01)\end{array}$ & $<0.001$ & & & & & $\begin{array}{l}0.006 \\
(0.003 \text { to } 0.009)\end{array}$ & $<0.001$ \\
\hline
\end{tabular}

Conditional BMI was estimated from current BMI regressed on adolescent BMI

Model 1 is a base model examining association between BMD and each of four explanatory variables (adolescent BMI, adulthood BMI, adulthood fat mass, and adulthood lean mass), adjusting for sex, age at the first wave of data collection (W1) in 2003-2005 (adolescence), age at the second and third waves (W2/3) in 2009-2012 (current/adulthood), height at W1 (cm), and height at W2/W3 (cm)

Model 2 examined association between adolescent BMI $\left(\mathrm{kg} / \mathrm{cm}^{2}\right)$ and adulthood BMD $\left(\mathrm{g} / \mathrm{cm}^{2}\right)$ adjusting for current BMI, sex, age at W1, age at W2/3, height at W1, and height at W2/W3

Model 3 examined association between adolescent BNU and adulthood BMD, adjusting for current FMI $\left(\mathrm{kg} / \mathrm{m}^{2}\right)$, current $\mathrm{LMI}\left(\mathrm{kg} / \mathrm{m}^{2}\right)$, sex, age at W1, and age at W2/3, height at W1, and height at W2/W3

Model 4 examined association between adolescent BMI and adulthood BMD, adjusting for conditional BMI, sex, age at W1, age at W2/3, height at W1, and height at $\mathrm{W} 2 / \mathrm{W} 3$

LS lumbar spine, BMI body mass index $\left(\mathrm{kg} / \mathrm{m}^{2}\right), F M I$ fat mass index $\left(\mathrm{kg} / \mathrm{m}^{2}\right.$, log-transformed), $L M I$ lean mass index $\left(\mathrm{kg} / \mathrm{m}^{2}\right)$

\section{Discussion}

There were less underweight young adults from this transitional rural community compared to during adolescence. Although these young adults on average had low bone mass, there was no clear evidence for an association between bone mass during young adulthood and thinness during adolescence when adjusted for current fat and lean mass. There was stronger evidence for a positive association between bone mass and lean mass than fat mass in young adulthood.

\section{Comparison with previous research}

While there are a number of studies examining association between bone mass in later life and birthweight, there are relatively few studies focusing on the long-term effects of nutritional status during adolescence on adult bone mass [8]. The New Delhi Birth Cohort examined the associations between bone mass during adulthood (age 33-39) and early life height and weight [25]. This cohort also had low BMI $\left(15.1 \mathrm{~kg} / \mathrm{m}^{2}\right.$ for boys and $15.4 \mathrm{~kg} / \mathrm{m}^{2}$ for girls) at age 11 , although by age 3339 , the average BMI had increased to above 25 . The study found positive associations between femoral neck and lumbar spine BMC and aBMD during adulthood and BMI at age 11, but similarly to our findings, these associations were attenuated upon adjustment for adult BMI. They also assessed changes in BMI in infancy, childhood, and adolescence and found that the change in BMI during adolescence was most strongly associated with adulthood bone mass. In our previous analyses, we found no strong evidence for a positive association between areal bone mineral density as young adults and early life nutritional supplementation [26].

The study subjects in the APCAPS gained weight between late adolescence and young adulthood. The Penn State Young Women's Health Study compared healthy women who gained weight in late adolescence (17-22 years) to those who had stable weight [27]. Those who gained weight had higher aBMD and greater bone cross sectional area in proximal femur shaft. This result is in line with our findings where larger gain in BMI during young adulthood is associated with higher aBMDs. Of note, their study also found that the bone strength index decreased in women who became overweight during late adolescence and suggested a potential negative effect of excess weight gain during adolescence on bone strength. 
Studies have suggested different patterns of associations between aBMD and fat and lean mass [14, 28-30]. In our study, there was no strong evidence for positive associations between aBMDs and fat mass. On the other hand, there was more consistent evidence for a positive association between aBMD and lean mass than fat mass, similarly to previous studies assessing relative contributions of fat and lean mass to bone mass accrual $[28,29]$.

It is important to note that aBMD in this study population was generally lower than values for bone mass values for young adults reported in a national DXA study in India [25]. The individuals with current BMI in the normal range had aBMD values closer to the national reference values than those with lower BMI values [25]. The current study found stronger evidence for an association between bone mass in young adulthood and current BMI than adolescent BMI. The weight gain during late adolescence may not have been sufficient for some of the study participants to achieve full catch-up growth. It is also possible that weight-bearing physical activity level was not high enough during late adolescence and young adulthood in this population.

\section{Strengths and limitations}

The main strength of this study is the availability of longitudinal data on height and weight, allowing the assessment of long-term effects of undernutrition during adolescence on bone mass in young adulthood. The study subjects experienced a unique circumstance where nutritional status of the study subjects improved greatly toward the end of the skeletal growth phase due to socioeconomic development in their villages. This setting allowed for an assessment of potential mitigation of the effects of undernutrition in early adolescence through improved nutritional status in late adolescence and young adulthood. Another strength of the study was the use of fat and lean mass from DXA scans to understand how different types of body mass may be distinctly associated with bone mass.

The study also had some limitations. The DXA measurements were not performed during adolescence, making it less clear whether and how bone mass improved, as weight, fat mass, and lean mass increased during adolescence. However, the association between body size and bone mass has been shown repeatedly in previous studies [14, 27], and therefore, it is reasonable to assume that the study subjects who were mostly underweight during adolescence also had lower zscores for bone mass for their age than healthier adolescents. Finally, due to a lack of detailed nutritional and activity data from W1, we could not explore long-term effects of lifestyle risk factors during adolescence that may have been important for skeletal growth.

\section{Conclusions}

In healthy individuals, much of bone mass accrual occurs during adolescence. As socioeconomic development continues in low- and middle-income countries, many children and adolescents are experiencing the effects of nutritional transition. Our findings suggest that weight gain combined with improvement in lean mass in young adulthood may be able to help mitigate adverse effects of undernutrition during adolescence on bone mass in young adulthood.

Acknowledgments We thank our dedicated field teams led by Santhi Bogadi and the study participants who made this study possible.

Author contributions $\mathrm{MM}$ analyzed the data and wrote the first draft of the manuscript. MM has primary responsibility for the final content of the manuscript. HK, BK, JCW, KVR, PP, VG, GKW, AA, DP, KVRS, GDS, YBS, and SK contributed to the design of the study; HK, BK, PP, VG, GKW, AA, KVRS, and SK contributed to the delivery of the study. GBP helped with the statistical analyses and conceptualization of the analysis.

\section{Conflicts of interests None.}

Open Access This article is distributed under the terms of the Creative Commons Attribution 4.0 International License (http:// creativecommons.org/licenses/by/4.0/), which permits unrestricted use, distribution, and reproduction in any medium, provided you give appropriate credit to the original author(s) and the source, provide a link to the Creative Commons license, and indicate if changes were made.

\section{References}

1. Bachrach LK (2001) Acquisition of optimal bone mass in childhood and adolescence. Trends Endocrinol Metab 12:22-28

2. Heaney RP, Abrams S, Dawson-Hughes B et al (2000) Peak bone mass. Osteoporos Int 11:985-1009. doi:10.1007/s001980070020

3. Bailey DA, McKay HA, Mirwald RL et al (1999) A six-year longitudinal study of the relationship of physical activity to bone mineral accrual in growing children: the university of Saskatchewan bone mineral accrual study. J Bone Miner Res 14:1672-1679. doi:10.1359/jbmr.1999.14.10.1672

4. Bailey DA, Faulkner RA, McKay HA (1996) Growth, physical activity, and bone mineral acquisition. Exerc Sport Sci Rev 24: 233-266

5. Subramanyam MA, Kawachi I, Berkman LF, Subramanian SV (2010) Socioeconomic inequalities in childhood undernutrition in India: analyzing trends between 1992 and 2005. PLoS ONE 5: e11392. doi:10.1371/journal.pone.0011392

6. Subramanyam MA, Kawachi I, Berkman LF, Subramanian SV (2011) Is economic growth associated with reduction in child undernutrition in India? PLoS Med 8:e1000424. doi:10.1371/journal. pmed.1000424

7. Sachdev HS, Fall CH, Osmond C et al (2005) Anthropometric indicators of body composition in young adults: relation to size at birth and serial measurements of body mass index in childhood in the New Delhi birth cohort. Am J Clin Nutr 82:456-466

8. Schlüssel MM, dos Santos Vaz J, Kac G (2010) Birth weight and adult bone mass: a systematic literature review. Osteoporos Int 21: 1981-1991. doi:10.1007/s00198-010-1236-Z 
9. Martínez-Mesa J, Restrepo-Méndez MC, González DA et al (2012) Life-course evidence of birth weight effects on bone mass: systematic review and meta-analysis. Osteoporos Int. doi:10.1007/s00198012-2114-7

10. Baird J, Kurshid MA, Kim M et al (2011) Does birthweight predict bone mass in adulthood? a systematic review and meta-analysis. Osteoporos Int 22:1323-1334. doi:10.1007/s00198-010-1344-9

11. Bachrach LK, Katzman DK, Litt IF et al (1991) Recovery from osteopenia in adolescent girls with anorexia nervosa. J Clin Endocrinol Metab 72:602-606. doi:10.1210/jcem-72-3-602

12. Hotta M, Shibasaki T, Sato K, Demura H (1998) The importance of body weight history in the occurrence and recovery of osteoporosis in patients with anorexia nervosa: evaluation by dual X-ray absorptiometry and bone metabolic markers. Eur J Endocrinol 139:276283. doi:10.1530/eje. 0.1390276

13. Benetos A, Zervoudaki A, Kearney-Schwartz A et al (2008) Effects of lean and fat mass on bone mineral density and arterial stiffness in elderly men. Osteoporos Int 20:1385-1391. doi:10.1007/s00198008-0807-8

14. Ho-Pham LT, Nguyen ND, Lai TQ, Nguyen TV (2010) Contributions of lean mass and fat mass to bone mineral density: a study in postmenopausal women. BMC Musculoskelet Disord 11:59. doi:10.1186/1471-2474-11-59

15. Pongchaiyakul C, Nguyen TV, Kosulwat V et al (2005) Contribution of lean tissue mass to the urban-rural difference in bone mineral density. Osteoporos Int 16:1761-1768. doi:10.1007/ s00198-005-1921-5

16. Creighton DL, Morgan AL, Boardley D (1985) Brolinson PG (2001) weight-bearing exercise and markers of bone turnover in female athletes. J Appl Physiol Bethesda Md 90:565-570

17. Tandon B, Kapil U (1990) ICDS scheme-current status, monitoring, research and evaluation system. Indian J Public Health 34:41

18. Kinra S, Krishna KR, Kuper H et al (2013) Cohort profile: Andhra Pradesh children and parents study (APCAPS). Int J Epidemiol. doi:10.1093/ije/dyt128

19. The International Institute for Population Sciences National Family Health Survey: NFHS-2. http://www.rchiips.org/nfhs/nfhs2.shtml. Accessed 28 Sep 2014
20. Kinra S (2007) The effect of supplemental nutrition in pregnancy and early childhood on future risk of cardiovascular disease: long term follow up of a community trial. ph.d., University of Bristol

21. Cole TJ, Flegal KM, Nicholls D, Jackson AA (2007) Body mass index cut offs to define thinness in children and adolescents: international survey. BMJ 335:194. doi:10.1136/bmj.39238.399444.55

22. The World Health Organization (1995) Physical status: the use and interpretation of anthropometry. 364

23. Jacobson JA, Jamadar DA, Hayes CW (2000) Dual X-Ray absorptiometry recognizing image artifacts and pathology. Am J Roentgenol 174:1699-1705

24. Mukherjee A, Mathur A (2011) Population based reference standards of peak bone mineral density of indian males and females. ICMR Bull

25. Tandon N, Fall CHD, Osmond C et al (2012) Growth from birth to adulthood and peak bone mass and density data from the New Delhi birth cohort. Osteoporos Int 23:2447-2459. doi:10.1007/s00198011-1857-x

26. Matsuzaki M, Kuper H, Kulkarni B et al (2014) Life-course determinants of bone mass in young adults from a transitional rural community in India: the Andhra Pradesh children and parents study (APCAPS). Am J Clin Nutr 99:1450-1459. doi:10.3945/ajcn.113. 068791

27. Petit MA, Beck TJ, Hughes JM et al (2008) Proximal femur mechanical adaptation to weight gain in late adolescence: a Six-year longitudinal study. J Bone Miner Res 23:180-188. doi:10.1359/ JBMR.071018

28. Wang MC, Bachrach LK, Van Loan M et al (2005) The relative contributions of lean tissue mass and fat mass to bone density in young women. Bone 37:474-481. doi:10.1016/j.bone.2005.04.038

29. Ho-Pham LT, Nguyen UDT, Nguyen TV (2013) Association between lean mass, fat mass, and bone mineral density: a meta-analysis. J Clin Endocrinol Metab 99:30-38. doi:10.1210/jc.2013-3190

30. Timpson NJ, Sayers A, Davey-Smith G, Tobias JH (2009) How does body fat influence bone mass in childhood? a Mendelian randomization approach. J Bone Miner Res 24:522-533. doi:10.1359/ jbmr.081109 